\title{
LA CUESTIÓN DEL LÍMITE ENTRE EL HOMBRE Y EL ANIMAL EN EL PENSAMIENTO DE JACQUES DERRIDA
}

\author{
THE ISSUE OF THE LIMIT BETWEEN HUMAN \\ AND ANIMAL IN JACQUES DERRIDA'S \\ PHILOSOPHY
}

\author{
Enrique GONZÁLEZ GALLINAS \\ UNED
}

\begin{abstract}
Resumen: Quizás el binomio conceptual más sólido en filosofía y menos cuestionado es el que opone al hombre con el animal. La herencia cartesiana de una radical separación en base a algún criterio que se supone forma parte de la esencialidad del hombre, y que es recusado de forma categórica a los otros animales, puede rastrearse en los principales discursos de la modernidad y del pensamiento contemporáneo. En el presente artículo abordaremos el cuestionamiento que Derrida realizará del cercado en el que el hombre ha recluido al resto de los animales, y su denuncia del dogmatismo con el que unilateralmente se les ha negado aquello que el hombre mismo se ha otorgado en exclusividad. Y ello no para postular ningún continuismo biológico, nada más lejos en un pensador que precisamente ha encontrado en la diferencia y en lo heterogéneo su mayor estímulo filosófico, sino para pensar ese abismo en toda su complejidad y haciéndose cargo de su espesura de sus repliegues. El objetivo no es otro que el de predisponernos a otro pensamiento de los animales y replantearnos nuestro ser en el mundo con ellos.
\end{abstract}

Palabras clave: Derrida, Heidegger, humano, animal, esencialidad, límite.

\footnotetext{
*Correo electrónico: egonzalezgall@yahoo.es.
} 
AвSTRACT: The most robust and least controversial conceptual pair in philosophy is possibly that opposing man to animal. The Cartesian inheritance of a radical separation based on a criterion that is presumably part of the essentiality of humans, and is refused categorically to other animals, can be traced in the main speeches of modernity and contemporary thinking. In this article we will address the challenge that Derrida will make of the fence in which humans have secluded the other animals, and his denunciation of the dogmatism with which they have been unilaterally denied what man has granted exclusively to himself. And this is not in order to postulate any biological continuity; nothing could be farther from the intention of a thinker who has indeed found his strongest philosophical stimulus in difference and in heterogeneity; it is, rather, in order to consider this gulf in all its complexity and to become aware of density of its intricacies. The sole purpose is to persuade ourselves to think about animals in a different way and to reconsider our being in the world with them.

KeYwords: Derrida, Heidegger, human, animal, essentiality, limit.

\section{Introducción: El último confín metafísico}

Con especial relevancia desde Descartes, la filosofía ha recluido a los animales dentro de una categoría homogénea, idealizada, profundamente óntica, siendo habitual encontrarlos en los textos de filósofos próximos a nosotros reducidos a "el animal", con artículo singular determinado, a efectos de resaltar su contraposición sin ambages al hombre. Esta resuelta categorización, no exenta de violencia, condiciona cualquier tentativa de acercarse sin prejuicios a lo que desde diferentes discursos se refieren al emplear un nombre, "el animal", bajo el cual cuantitativamente se incluirían miles de millones de individuos taxonómicamente ordenados en millones de especies diferentes ${ }^{1}$, desde las ya extinguidas a las actualmente vivientes, y dentro de éstas, tanto las descubiertas e incorporadas a los saberes científicos, como las muchas que nunca llegarán a serlo, bien porque desaparecerán antes, o bien porque la extinción le acaezca a la propia especie humana.

\footnotetext{
1 "La evolución ha dado lugar a una enorme diversidad de especies en el reino animal. Los zoólogos han bautizado más de 1,5 millones de especies animales, y se describen miles más cada año. Algunos zoólogos creen que las especies conocidas hasta hoy solamente constituyen el $20 \%$ de la totalidad de animales vivos y menos del $1 \%$ de todos los que han existido en el pasado". Hickman, Cl. (dir.): Principios integrales de zoología, Madrid, Mc GrawHill, 2009, p. 199.
} 
Esta formidable e inconmensurable variabilidad en el darse o en el acontecer de lo vivo observable dentro del mundo de los animales, con sus diferencias tanto en el vivir como en el morir, no ha sido suficiente acicate para que desde la filosofía se emprendiese con rigor un cuestionamiento de los criterios a los que en cada ocasión se ha recurrido para consolidar el orden basado en el dualismo hombre-animal. Lejos de ello, los discursos filosóficos en su mayoría han procurado asestar en cada ocasión un corte más refinado para disipar cualquier duda sobre la pureza de una esencialidad de lo humano y de una esencialidad de lo animal. Esta esencialidad se ha caracterizado generalmente mediante la presuposición de la existencia de algún atributo que se considera como "lo propio del hombre", a la vez que es negado a los otros animales. No es de extrañar que tras ello surjan sospechas sobre el interés en mantener esta neta delimitación en relación a la propia configuración del sujeto, vislumbrando que, quizá, se trata de reforzar por medio de una cultura sacrificial la artificiosidad y compactación de éste. Como ejemplo de ello podemos citar el poder del "yo" en Kant, el habla, la mortalidad, la capacidad del "en cuanto tal" en Heidegger, la tenencia de un rostro en Lévinas, el poder borrar las huellas en Lacan, ejemplos todos ellos sobre los que Derrida reflexionará extensamente y en los que aquí no podemos detenernos (Derrida, 2008, capítulos II, III y IV).

Bien es cierto que puede aducirse que se trata de dos ámbitos diferenciados. Por un lado la ciencia nos aportaría información sobre la inmensa variabilidad de la región óntica del mundo animal, mientras que la investigación sobre la esencialidad sería propia de la ontología, debiéndose mantener entre ambos planos cierta tensión en virtud de sus diferentes alcances. ¿Pero cómo deben relacionarse? ¿Ha de atender el científico a las especulaciones filosóficas sobre su materia, y viceversa, el filósofo a las novedades que desde la ciencia pueda recibir, accediendo a modificar sus planteamientos si con ello resultan trastocados? Porque lo cierto es que en el asunto que nos ocupa, los avances en la investigación zoológica, y más específicamente en la Etología y la Primatología, aportan materiales suficientes como para reconsiderar esos supuestos en relación con los animales, los cuales además de en la filosofía pueden detectarse en diferentes ramas o escuelas de la propia ciencia. ${ }^{2}$ Veamos algún caso concreto de cómo se plantea esta relación.

\footnotetext{
${ }^{2}$ Como ejemplo, uno de los criterios diferenciadores que tradicionalmente se ha supuesto entre el hombre y los animales, tanto en Filosofía como en Etología, es el establecido en base a la capacidad o no de respuesta, siguiendo el ejemplo del autómata cartesiano. Los animales no responden, sino que reaccionan, no tienen acceso a la posibilidad de responder de forma
} 
Para Heidegger el científico especializado en las ciencias de la vida debe partir de presupuestos ontológicos, razón por la cual éstos no pueden provenir de sus investigaciones, sino que más bien las deben determinar. De ahí la justificación de la abstracción que se hace en la filosofía de la variabilidad que nos presenta la ciencia más descriptiva en relación con el mundo animal, y cierto hiato entre ambas que no será fácil superar. El contexto en el que este pensador abordó el problema fue el seminario Los conceptos fundamentales de la metafisica. Mundo, finitud, soledad, impartido en Friburgo en el semestre de invierno de 1929/1930. En su dilucidación de la pregunta por el mundo, y una vez descartadas la vía historicista en relación con la historia de la formación del concepto, por haberla tratado ya en De la esencia del fundamento, y la vía fenomenológica, que ya fue objeto de investigación en Ser y tiempo, emprenderá la vía comparativa, consistente en analizar las diferentes formas de relacionarse con el mundo que se dan en lo mineral, en lo animal y en lo humano. Dicha vía se desplegará partiendo de tres tesis sobre el mundo, las conocidas la piedra es sin mundo (weltlos), el animal es pobre en mundo (weltarm) y el hombre configurador de mundo (weltbilden). Sin poder seguir aquí el razonamiento heideggeriano en toda su riqueza, simplemente queremos subrayar algunos aspectos que conciernen a la relación entre los dos planos aludidos, el ontológico y el epistemológico, tal y como las propone Heidegger en este trabajo, al hilo de la pregunta por la procedencia de la tesis el animal es pobre en mundo, tesis cuya importancia en su razonamiento se evidencia en que precisamente empezará su investigación por ella y ocupará la mayor parte del seminario.

¿De dónde procede esta proposición: el animal es pobre de mundo? Volveremos a decir: de la zoología, pues trata de animales. Pero precisamente

\footnotetext{
libre, sino que en todo caso su respuesta es "precableada", determinada. Pero nos encontramos ante un mundo bastante proceloso, habiéndose aflojado significativamente las certezas que sobre los mecanismos de la motivación, por lo tanto de la respuesta, tanto furor hicieron en los comienzos del Etología. Recuerdan J. C. Gómez y F. Colmenares cómo un importante etólogo, Halliday, en 1983 finalizaba así el capítulo de una de sus obras dedicado al análisis de los mecanismos causales o motivacionales de la conducta: "Este capítulo habrá resultado de utilidad si ha servido para convencer al lector de que no existen principios unificadores o teorías generales ampliamente aceptadas en el estudio de la motivación. Probablemente el consenso sobre la naturaleza de los mecanismos motivacionales sea menor que en cualquier otra área de la etología". Gómez, C. y Colmenares F.: "La causación del comportamiento: modelos clásicos y causas externas", en Carranza, J. (dir.). Etología. Introducción a la ciencia del Comportamiento. Cáceres, Universidad de Extremadura, 1994, p. 41.
} 
porque trata sobre ello, esta proposición no puede ser resultado de su investigación, sino su presupuesto. Pues en este presupuesto se realiza al cabo una determinación previa de aquello que en general forma parte de la esencia del animal, es decir, una delimitación del campo dentro del cual tiene que moverse la investigación positiva de los animales. Pero si en la tesis se encierra un presupuesto para toda la zoología, entonces no puede obtenerse por primera vez mediante ésta. De ahí parece seguirse que en la discusión de esta proposición nos desprendemos de todos los ricos y enmarañados resultados que hoy ya ni siquiera el experto es capaz de dominar. Así parece. ¿Pero qué criterio tenemos entonces para la verdad de la tesis? ¿De dónde la obtenemos? ¿Es arbitraria o es una hipótesis que, después de todo, tiene que confirmarse con la investigación particular? (Heidegger, 2007, 237).

Sin duda Heidegger tuvo presente en su investigación los conocimientos más actualizados en zoología existentes en su época, dando muestras de una ingente erudición, tal y como puede comprobarse en el desarrollo de la tesis el animal es pobre en mundo. Además de las citas de obras de destacados biólogos coetáneos, resaltará explícitamente, como "dos pesos esenciales en la biología", a Hans Driesch y Jacob Johann v. Uexküll (Heidegger, 2007, \$61, b). Pero dada la esencialidad de esta proposición, el animal es pobre en mundo, para Heidegger su origen no puede provenir de la zoología, sino que debe ser anterior, incluso determinarla. La "determinación previa" adquiere su fundamento de su carácter metafísico, el cual procede a su vez del temple de ánimo del verdadero filosofar. Nuestro actuar, dirá Heidegger, es aquí un preguntar determinado (Heidegger, 2007, 233), y debe anteponerse, incluso hacer abstracción, de todo el conjunto de teorías que puedan haberse formulado sobre los animales, los "ricos y enmarañados resultados" que ya ni siquiera los científicos más expertos podrían dominar. Parece como si la filosofía tuviese como misión propia el ordenar y deslindar el campo en que deben actuar los científicos, facilitándoles con ello el acceso y dominio de aquello que investigan. Evidentemente sería ingenuo objetarlo aludiendo a un supuesto empirismo neutro, desde cuya imparcialidad poder aprehender lo fenomenológico en su pureza, pero entonces, toda vez que queda excluida la posibilidad de esa imparcialidad, queda por examinar qué es lo que ha de determinar la firmeza de esta proposición. Pero por otro lado, Heidegger señalará que dicha tesis "proviene de la zoología”, por lo que se verá obligado a reconocer que "nos movemos en círculo" (Heidegger, 2007, 237-238), y con esa circularidad en el pensar precisamente probamos que estamos filosofando, en 
contraposición con el avanzar en línea recta que caracteriza el "entendimiento vulgar" o científico. Pero lo esencial de esa circularidad "no es recorrer una periferia y regresar al punto de partida", dirá Heidegger, sino "mirar hacia el centro" del círculo. Por tanto se trata de un pensamiento que podemos considerar, más que circular, centrípeto, y si hubiese algo en el centro del pensamiento filosófico, no encontramos un candidato más plausible que el ser del hombre, en su doble genitivo, por lo que estamos tentados a sostener que un pensamiento profundamente humanista determinaría la investigación sobre los animales a través del presupuesto de su esencialidad.

En definitiva, sobre el origen de la tesis de la pobreza de mundo del animal, Heidegger nos dirá que "ni procede de la zoología ni puede discutirse independientemente de la zoología". La proposición precisa de una "determinada orientación" conforme a la biología y a la zoología, pero la "confirmación de su dirección no la tiene en ellas". En el fondo se vislumbra el problema de la relación entre metafísica y ciencia, que en sus aspectos prácticos se concreta en cómo el pensamiento especulativo puede sacar a la ciencia positiva de su reduccionismo, y Derrida reconocerá el mérito del intento heideggeriano de mantener a raya a cualquier biologismo (Derrida, 2008, 170), pero también de cómo la metafísica puede llegar a embridar a una ciencia que apunta allí donde el propio discurso metafísico se resquebraja, como por lo demás el seminario aludido es un memorable ejemplo. La rica formación en biología de la que da muestras Heidegger en este seminario, es puesta al servicio de esta tesis determinante del abismo entre el hombre y el animal, sosteniendo la imposibilidad del animal de acceder al en cuanto tal de los entes, quedándose reducidos a su anillo de desinhibición, a su mundo circundante o Umwelt, término puesto en circulación por el antes citado von Uexküll.

Quizá esta sutilización metafísica del abismo entre el hombre y el animal, acontecida con especial ímpetu desde los albores de la Modernidad y al socaire de cualquier turbulencia que le pueda llegar del mundo de las ciencias más desprejuiciadas, haya llevado a Derrida a entrever que detrás se disimula uno de los más importantes pilares que han sostenido al discurso filosófico hegemónico ${ }^{3}$,

\footnotetext{
${ }^{3}$ Creemos conveniente matizar este término e indicar, como nos recuerda Cristina de Peretti, que Derrida "no entiende nuestra tradición filosófica como un discurso homogéneo", citando al propio Derrida: "[...] con frecuencia he insistido en [...] la no identidad de algo como la metafísica. Hablar como lo he hecho de una 'estructura dominante' en la historia de la metafísica es sugerir que dicha historia es un proceso, por consiguiente, una inestable relación de fuerzas cuya conflictualidad misma le prohíbe referirse tranquilamente a su identidad, etc."
} 
si no el que más, por lo que su cuestionamiento habrá sido estratégico a lo largo de su obra filosófica:

La "cuestión-de-la animalidad" no es una cuestión entre otras, por supuesto. Si la considero decisiva, como se dice, desde hace mucho tiempo, en sí misma y por su valor estratégico, es porque, difícil y enigmática en sí misma, representa también el límite sobre el cual se suscitan y determinan todas las otras grandes cuestiones y todos los conceptos destinados a delimitar "lo propio del hombre", la esencia y el porvenir de la humanidad, la ética, la política, el derecho, los "derechos del hombre", el "crimen contra la humanidad”, el "genocidio”, etcétera (Derrida, J., y Roudinesco, E., 2009, 73-74).

Nos encontramos ante un factor común del discurso dominante, el cual en sus diferentes variantes mantendría compactos prejuicios e interesadas presuposiciones sobre esa parte del mundo a la que se refiere como "el animal", propiciando así el alzado de un muro con el que circunscribir con mayor fiabilidad el problema de la dilucidación de la esencia del hombre o "lo propio del hombre". La prescripción de esta aguda divisoria, cuando menos nos permitiría concentrar nuestras pesquisas acerca de ese "lo propio del hombre" en base a incontestados criterios de exclusión, y en concordancia con el dualismo en torno al cual se ha ido configurando la arquitectónica del pensamiento occidental, al igual que otros muchos pares de opuestos tales como caos-cosmos, naturaleza-cultura, barbariecultura, cuerpo-alma, etc.

Todos los gestos deconstructores que intenté respecto de los textos filosóficos, en particular los de Heidegger, consisten en cuestionar el desconocimiento interesado de lo que se llama el Animal en general, y la manera en que dichos textos interpretan la frontera entre el Hombre y el Animal (Derrida y Roudinesco, 2009, 73-74).

De Peretti, C.: "A propósito de los animales", en Cragnolini, M. B. (dir.): Por amor a Derrida. Buenos Aires, La Cebra, 2008. 
Porque efectivamente, aunque como indicábamos más arriba las referencias bibliográficas científicas en el seminario heideggeriano aludido son profusas, sin embargo la metafísica seguirá rigiendo cualquier pensamiento sobre los animales, tal y como veíamos que el propio Heidegger reconoce, lo que puede conllevar el cuestionamiento de quien no se cińa a esa determinación, de quien ose guiarse en sus investigaciones científicas soslayando esos presupuestos metafísicos. ${ }^{4}$

\section{Preguntarse por el hombre, preguntarse por el animal}

Para Heidegger no hay duda de los estrechos vínculos entre el pensamiento del animal y el pensamiento del hombre.

Por eso, mediante aquella caracterización del mundo, en apariencia puramente negativa, en la discusión del no tener mundo del animal, la esencia propia de nosotros mismos ha quedado ya continuamente realzada, si bien no en una interpretación explícita. Lo quisiéramos o no, nosotros mismos también estábamos allí en el objetivo [...]. Y de este modo, la caracterización supuestamente sólo negativa -la discusión del no tener mundo- quizá repercutirá sobre todo en cuanto comencemos a exponer la esencia del mundo con miras a la formación del mundo del hombre (Heidegger, 2007, 328).

Si la filosofía ha reforzado su concepción de lo que sea el hombre por el camino expeditivo de recusar a los animales los atributos determinados como esenciales en aquel, para Derrida su cuestionamiento aboca a remover las certezas asentadas a ambos lados del límite. Su estrategia será la de comenzar inquiriéndose por el propio $y o$, pero desplegando una batería de interrogantes acerca del animal, al objeto de evidenciar la interesada premura con la que el pensamiento se ha deslizado por tan espinosa cuestión, quizá por llegar cuanto antes y por atajos al motivo antropológico.

\footnotetext{
${ }^{4}$ Como ejemplo las referencias heideggerianas al antidarwinismo de von Uexküll. Heidegger, M.: Los conceptos fundamentales de la metafísica. Mundo, finitud, soledad. Ed. cit., p. 318.
} 
El animal en general ¿qué es? ¿Qué quiere decir eso? ¿Quién es? ¿A qué corresponde "eso"? ¿A quién? ¿Quién responde a quién? ¿Quién responde al nombre común, general y singular de lo que ellos denominan así tranquilamente "el animal"? ¿Quién responde? La referencia de lo que me concierne y me mira en nombre del animal, lo que se dice entonces en nombre del animal cuando se recurre al nombre del animal: es lo que se trataría de exponer al desnudo, en la desnudez o el desamparo de quien dice, abriendo la página de una autobiografía, "he aquí quien soy". "Pero yo, ¿quién soy?" (Derrida, 2008, 68).

Así como abundan las preguntas sobre el hombre en la filosofía, las referidas a los animales llevan tiempo en peligro de extinción, y cuando se plantean quien las responde es un apresurado hombre. ${ }^{5}$ A través de estos interrogantes Derrida pretenderá evidenciar la ligereza con la que emitimos nuestras proposiciones ontológicas sobre los animales por el simple mérito de haberles conceptualizado inflexiblemente bajo un nombre, "el animal". Mientras, en paralelo, pretende subrayar la dificultad de responder a la manida pregunta de "quién soy", pregunta que en todo caso, para Derrida, exige ser contestada desde la más exigente racionalidad, desde la desnudez (aludiendo de paso con ello a la circunstancia de que la desnudez también ha sido considerada como criterio diferenciador entre el hombre y los animales), es decir desde la sinceridad radical del que dice exponerse al desnudo a través de una verdad desnuda, y que a falta de algo mejor dice "heme aquí quien soy".

Si tal y como sostienen importantes discursos filosóficos a los que se podría considerar fiduciarios de la tradición cartesiana, los animales no podrían responder a la interrogación acerca del ¿Quién soy?, en función de su privación general de la capacidad de respuesta y siguiendo la metáfora del autómata, Derrida se pregunta si tal capacidad está al alcance del hombre, y en ese caso cuáles serían los criterios por los que podría diferenciarse de forma meridiana entre lo que se concibe como una respuesta, que desde sí se reclama libre y responsable, y lo

\footnotetext{
${ }^{5}$ Como ejemplo de estas prisas, podemos citar las de Descartes: “¿Qué creí entonces ser? Un hombre, naturalmente. Pero ¿qué es un hombre? ¿Diré que es un animal racional? No, puesto que se habría de investigar qué es animal y qué es racional, y así me deslizaría de un tema a varios más difíciles, y no me queda tiempo libre para gastarlo en sutilezas de este tipo." Descartes, R.: Meditaciones metafísicas. Trad. Juan Gil Fernández y Consuelo Bergés, Barcelona, Folio, 2002, p. 36.
} 
que se entiende como una reacción a un sistema complejo de estímulos, tanto conscientes como inconscientes, y que funcionarían como una especie de prótesis óntica con la que más o menos pretendemos salir al paso allí donde se nos requiere dar cuenta de nuestra ipseidad.

Acorde con su proceder filosófico de alumbrar allí donde la deconstrucción se da, Derrida se planteará si lo que el hombre se arroga a sí mismo como criterio diferenciador frente a los animales se presenta de forma clara y pura, o si por el contrario responde más bien a una estratégica idealización, aquella determinación a la que aludía Heidegger, la cual, desde el momento en que es contestada desde un "yo soy...", no puede evitar incluir los elementos habituales en una autobiografía, arriesgándose con ello a no ser más que una fabulación, una fabulación animal podría decirse, en todos los sentidos de este epíteto.

Por otro lado, aunque el "Pero yo ¿quién soy?” nos interpele desde Descartes, recogiendo la tradición socrática del "conócete a ti mismo", y siendo interrogante principal al que la filosofía ha tratado de responder, Derrida nos insta a atender a la doble significación del suis francés, como primera persona del presente de indicativo del verbo ser y del verbo seguir en su traducción castellana:

[...] qui suis-je? o que-suis je? [“¿(A) quién estoy si(gui)endo?” o “¿qué estoy si(gui)endo?”]. La confusión de este equívoco seguiría siendo aquí intraducible para siempre, en lo que permanece pequeño, lo pequeño, la palabra pequeña que está en medio de esa proposición interrogativa con tres palabras, a saber, el pequeño homónimo suis que, en la primera persona del presente de indicativo, conjuga más de un verbo, être (ser) y suivre (seguir): ¿(a) quién estoy si(gui)endo? “¿(A) quién (es al que) estoy si(gui)endo?” . Este pequeño, este pequeño que viene como tercero en discordia y hace de cópula, al decir "estoy si(gui)endo", "si(gui)endo estoy", "(a) quién estoy si(gui)endo", "que estoy si(gui)endo", sin permitirnos ninguna garantía entre el sujeto y él mismo, entre el sujeto y su atributo, incluso entre el sujeto y el objeto sobre el cual, literalmente, se encarniza o se engaña en el curso de una caza especular: ¿¿de dónde viene y a dónde va? (Derrida, 2008, 81-82). 
Para Derrida, previamente a la "cuestión del ser como tal, del esse y del sum, del ego sum", asuntos que se han considerado como propios de la filosofía en cuanto disciplina especulativa sobre las esencias, habría que hacerse cargo de la cuestión del seguir, "de la persecución o de la seducción del otro, que sigo o que me sigue, que me sigue mientras yo lo o la sigo" (Derrida, 2008, 82). En el fondo se trata de pensar lo que determina nuestro pensar, lo que puede ocultarse detrás de lo que hacemos cuando filosofamos, verbigracia cuando perfilamos metafísicamente el ámbito de la ciencia. Para Derrida no podemos pensarnos si no nos pensamos en devenir con los otros, y dentro de esa otredad no puede excluirse a los otros animales ni al animal que somos. En ese ejercicio rastreará las connotaciones seductoras, afines al engaño, que subyacen en todo discurso del "yo soy", en cuanto "astucia onto-lógica" que "esconde ya el interés transitivo, el seguir de un 'estoy si(gui)endo': estoy si(gui)endo (a) alguien distinto, soy seguido por alguien distinto, persigo un deseo o un proyecto, yo doy y a la vez me doy caza a mí mismo" (Derrida, 2008, 87). Detrás de la simplicidad de la aparente desnuda confesión que se despliega en el "yo soy", según resuena en lengua francesa, Derrida se detiene a subrayar la riqueza de matices que introduce su doble significación en cuanto ser y seguir:

¿Qué significa "seguir", "seguiră”, "continuará", "proseguir”, incluso "perseguir”? ¿Qué hacemos cuando seguimos? ¿Qué hago cuando sigo? ¿Cuándo voy tras alguien o algo, tras un animal que algunos consideran un algo que no es necesariamente un alguien? ¿Qué quiere decir "ir tras"? (Derrida, 2008, $71)$.

Efectivamente aquello que sigo, o que persigo, condiciona la respuesta al propio cuestionamiento del quién soy, la determina. "No hay que excluir, nos dirá Derrida, que el mismo ser vivo sea a la vez seguidor y seguido, cazador que se sabe cazado, seductor y seducido, perseguidor y acosado" (Derrida, 2008, 72), siendo como las dos fuerzas de una misma estrategia, del mismo movimiento, incluso conjugándose en el mismo animal y en el mismo momento. El cazadorpredador en sus persecuciones proyecta sus interrogantes hacia aquello que (per) sigue, pero no puede evitar los efectos colaterales del "yo soy", impidiendo el hábito de una cancelación rápida de las preguntas también en este caso una razonada y sincera o desnuda respuesta, dando más bien lugar a lo que entendemos 
precisamente como una reacción, es decir aquello que desde Descartes se postularía como característico del animal.

\title{
3. Lo propio del hombre y lo propio del animal
}

En su obra Más allá del bien y del mal Nietzsche nos dice lo siguiente:

\begin{abstract}
El hombre, animal complejo, mendaz, artificioso e impenetrable, inquietante para los demás animales, no tanto por su fuerza cuanto por su astucia y su inteligencia, ha inventado la buena conciencia para disfrutar por fin de su alma como de un alma sencilla; y la moral entera es una esforzada y prolongada falsificación en virtud de la cual se hace posible en absoluto gozar del espectáculo del alma. Desde este punto de vista acaso formen parte del concepto "arte" más cosas de las que comúnmente se cree (Nietzsche, 1983, $\$ 291)$
\end{abstract}

Autoerigiéndose en soberano, cual Robinson Crusoe, el hombre simplifica el mundo, empezando por él mismo, englobándose artísticamente en una categoría artificiosa con la que pretenderá dominar la realidad. La esencialidad pretendida del hombre, y que vemos cómo Nietzsche la atribuye al arte, al artificio, va a ser perseguida de variadas maneras por el discurso hegemónico occidental. Son varios los candidatos que se han ido postulando como "lo propio del hombre", entre ellos la moral, la política, el lenguaje, la organización en sociedad, la razón, la capacidad de abstracción y conceptualización, la dignidad, el rostro, el mirar, la mortalidad, la inmortalidad...Todas ellas en mayor o menor medida van a ser abordadas por Derrida, intentando desmontarlas desde las grietas que se vislumbran entre sus certezas.

Sin embargo, de ello no puede deducirse la renuncia a pensar la posible existencia de un "propio del hombre", (e ironiza sugiriendo que de tener que identificar algún "lo propio del hombre", la lengua francesa -y la castellana también-garantizaría cuando menos uno: sólo el hombre puede hacer animaladas o bestialidades, puesto que los hechos calificados así no hay forma de atribuírselos a los animales sin incurrir en un claro antropomorfismo, "el más característico"), 
sino que intentará demostrar cómo lo que hasta ahora ha sido considerado como tal en la cultura o la filosofía "no están rigurosamente reservados a eso que nosotros, los hombres, entendemos por el hombre" (Derrida, 2008, 81), bien porque el hombre no disponga de ese tal "lo propio del hombre" de forma pura, o bien porque algunos animales, especies o individuos, sí puedan tenerlo.

Por otro lado Derrida será sensible a la circunstancia de que si bien es cierto que dentro del discurso ontológico dominante sobre los animales hay un implícito programa de homogeneización, las formas a través de las cuales el hombre ha pretendido interiorizar conceptualmente a los animales no han estado exentas de las mayores contradicciones: "bondad absoluta porque natural, inocencia absoluta antes del bien o del mal, el animal sin culpa ni defecto (ésta sería -nos dirá Derrida- su superioridad como inferioridad) pero asimismo el animal como mal absoluto, crueldad, salvajismo asesino" (Derrida, 2008, 81).

Uno de estos "lo propio del animal" que analiza, y como casi siempre con el estigma de su privación en contraposición con los hombres, sería su supuesta incapacidad de sońar, con toda la importancia que este acto vital tiene en relación con la conciencia, el inconsciente, etc. A su juicio no habría mucho reparo en aceptar que algunos animales tienen experiencias oníricas y de que no todos sueñen de la misma manera, tanto si atendemos a nuestras rutinas más domésticas con perros y gatos, como si prestamos oídos a los saberes científicos, donde los avances técnicos han permitido detectar en algunas especies fases propicias para sueño mediante encefalogramas que miden la intensidad de la actividad mental.

Se desvela así la forma general que el tratamiento de estas cuestiones adquirirá en Derrida, introduciéndose ya la crítica a este intento de nivelación de los animales:

[...] ¿qué sentido tiene -y con qué derecho- poner este nombre en singular, el animal, allí donde una experiencia tan esencial como el sueño y, por consiguiente, la relación entre la conciencia, el subconsciente, el inconsciente incluso la representación y el deseo separa a tantos animales entre sí, pudiendo en cambio reunir a lo que se denomina el hombre con los animales? ¿Acaso no es preciso decir "los animales" renunciando de antemano a cualquier horizonte de unificación para un concepto del animal al que se 
podría contraponer cualquier cosa que a la vez fuese identificable? (Derrida, 2008, 79-80).

Del mismo modo, esta lógica podría aplicarse a otras preguntas que para este pensador serían análogas "en su forma, sus premisas, sus apuestas", preguntas que habitualmente se han despachado categóricamente, como intentando soslayar el riesgo de que socaven nuestras convicciones antropocéntricas:

[...] “ipiensa el animal?”, “¡tiene el animal representaciones?”, ¿ ‘tiene un "yo", imaginación, una relación con el porvenir como tal? ¿Posee el animal no sólo signos sino también un lenguaje y qué lenguaje? ¿El animal muere? ¿Ríe? ¿Llora? ¿Sabe lo que es el duelo? ¿Se aburre? ¿Miente? ¿Perdona? ¿Canta? ¿Inventa? ¿Compone música? ¿La toca? ¿Juega? ¿Brinda hospitalidad? ¿Ofrece? ¿Da? ¿Tiene manos? ¿Ojos, etc.? ¿Pudor? ¿Ropa? ¿Y el espejo?... (Derrida, 2008, 79-80).

Para Derrida estos interrogantes, que considerará "inmensos por su historia, sus presupuestos, la complejidad de lo que ponen en juego" (Derrida, 2008, 79-80), se han dirigido todos ellos a intentar descubrir, o más bien prescribir, una pretendida esencialidad del animal, algo así como "lo propio del animal", teniendo una correspondencia directa con aserciones afirmativas al dirigirse a "lo propio del hombre". En general su estrategia no pasará por contestarlas con un mero sí afirmativo y sin más, el cual podría acompañar con referencias a la abundante bibliografía científica que pueda existir, sino que buscará el modo en que puedan resonarnos desde otros ángulos:

¿Cómo, en cierto modo, poner un bemol a la clave de estas interrogaciones y cambiar la música? [...] ¿Cómo hacer que se oiga aquí una lengua o una música inaudita, bastante inhumana en cierto modo, y no para hacerme pasar aquí por el representante o el emancipador de una animalidad olvidada, ignorada, desconocida, perseguida, cazada, pescada, sacrificada, 
sometida, criada, aparcada, hormonizada, transgenetizada, explotada, consumida, devorada, domesticada, sino para hacerme entender en una lengua que sea una lengua, ciertamente, y no esos gritos inarticulados, ruidos, rugidos, ladridos, maullidos, píos insignificantes que tantos hombres atribuyen al animal, una lengua finalmente cuyas palabras, conceptos, melodía, acento sean bastante ajenos a lo que, en todas lenguas humanas, habrá albergado tantas animaladas sobre el susodicho animal? (Derrida, 2008, 80-81).

Necesidad por lo tanto de atisbar "lo otro" de otras formas de idioma ${ }^{6}$, un deseo de idioma que surge cuando el pensar fuerza al lenguaje heredado en su tránsito por nuevas sendas que le acerquen a estas preguntas, a estas respuestas, injertadas ya en otra textualidad. Un lenguaje que estuviese al margen de la lógica hasta ahora predominante en el discurso sobre el animal, una lógica de la que Derrida sospechará que se encuentra dentro de lo que se podría calificar como estrategias animales, "en el sentido humano de la palabra", en el contexto de una general lucha "entre presuntas especies" (Derrida, 2008, 81).

\section{Limitrofía: merodeando en los límites entre el hombre y los otros animales}

En el mundo animal existe una gran cantidad de estructuras diferentes. Entre el protozoario, la mosca, la abeja, el perro, el caballo, los límites se multiplican, sobre todo en la organización "simbólica", en el cifrado o la

\footnotetext{
${ }^{6}$ Deseo de idioma o de deseo de poder leer otros textos: "lo que todavía llamo texto por razones parcialmente estratégicas [...] ya no sería [...] un corpus finito de escritura, un contenido enmarcado en un libro o en sus márgenes, sino una red diferencial, un tejido de huellas que remiten indefinidamente a algo otro, que están referidas a otras huellas diferenciales. A partir de ese momento, el texto desborda, pero sin ahogarlos en una homogeneidad indiferenciada, sino complicándolos por el contrario, dividiendo y multiplicando el trazo, todos los límites que hasta aquí se le asignaban, todo lo que se quería distinguir para oponerlo a la escritura (el habla, la vida, el mundo, lo real, la historia, ¡Qué sé yo aún!, todos los campos de referencia física, psíquica -consciente e inconsciente-, política, económica, etc.)”. J. Derrida, Parages (1986), cita recogida en De Peretti, C. y Vidarte, P.: Derrida. Madrid, Ediciones del Orto, 1998, p. 71.
} 
práctica de los signos. Si me inquieto por una frontera entre dos espacios homogéneos, por un lado el hombre y por el otro el animal, no es para pretender, neciamente, que no hay límite entre los "animales" y el "hombre", sino porque sostengo que hay más de un límite: muchos límites. No hay una oposición entre el hombre y el no-hombre; entre las diferentes estructuras de organización de lo viviente hay muchas fracturas, heterogeneidades, estructuras diferenciales (Derrida y Roudinesco, 2009, 77).

Como indicábamos más arriba, para Derrida el límite entre el hombre y los animales afecta a asuntos fundamentales que nos conciernen, razón por la que resultará primordial acercarse y merodear, o derridianamente destinerrar, por ese límite sin desfallecer cediendo a clausuras precipitadas. Para el filósofo francoargelino el fin no será tanto poner de relieve que en el mundo de los animales puedan darse, en diferentes grados, pruebas de existencia de las diversas capacidades que les hubiesen sido sustraídas por la filosofía a lo largo de la historia, sino más bien evidenciar que el hombre tampoco dispondría de las mismas de forma absoluta, sino en función de situaciones, de pulsiones, de afecciones, de su grado de desarrollo en definitiva, y nunca dándose de una manera pura.

La única regla que, por el momento, creo que hay que adoptar aquí es la de, por una parte, desconfiar de los límites oposicionales habitualmente acreditados entre lo que se llama naturaleza y cultura, naturaleza/ley, phúsis/ nomos, Dios, el hombre y el animal o incluso en torno a algo "propio del hombre", y por otra parte, sin embargo, no mezclarlo todo, no precipitarse, por analogismo, hacia semejanzas e identidades. Cada vez que se vuelve a poner en cuestión un límite oposicional, lejos de concluir de ahí en la identidad, hay que multiplicar, por el contrario, la atención a las diferencias, refinar el análisis en un campo restructurado. ${ }^{7}$

7 Derrida, J., "El bien soberano, o estar malo de ganas de soberanía”, en Archipiélago (Barcelona) no 75, 2007, pp. 105-106. 
Para ello tratará de ahondar desde y en otra lógica del límite entre lo humano y lo animal, en la "experiencia propiamente transgresora, si no transgresiva de una limitrofía", término con el que pretenderá dar cuenta de lo que "acerca los límites, pero también lo que alimenta, se alimenta, se mantiene, se cría y se educa, se cultiva en los bordes del límite". Conforme a esta nueva lógica, se trataría de analizar "lo que se desarrolla y crece en el límite", además de aquello que lo alimenta (trophos), "lo genera, lo hace crecer y lo complica" (Derrida, 2008 , 46). Debe insistirse en que su propuesta no implica en absoluto "borrar el límite", en cuyo caso tras un rodeo acabaríamos de nuevo en un desactivado campo para el pensamiento, sino que, al contrario, pretende "multiplicar sus figuras, complicar, espesar, desalinear, plegar, dividir la línea precisamente haciéndola crecer y multiplicarse" (Derrida, 2008, 46). En ningún caso plantea "impugnar, por poco que sea, el límite entre el Hombre con $\mathrm{H}$ mayúscula y el Animal con A mayúscula” (Derrida, 2008, 46), añadiendo que él no ha creído nunca en "ninguna continuidad homogénea entre lo que se llama el hombre y lo que él denomina animal" (Derrida, 2008, 46). En este sentido al continuismo biológico lo califica de estrafalario, dirigiendo sus reflexiones sin piedad contra "este alegato por lo que tiene de falso" (Derrida, 2008, 47), los propios animales, nos dirá, "saben" bien que esta diferencia se da. Por el contrario, vemos cómo la cuestión se tornará interesante para Derrida en la determinación del "número, la forma, la estructura, y el espesor estratificado de ese límite abisal, de sus bordes" (Derrida, 2008, 47). Su enjundia se incardina no en si existe o no límite, sino "en pensar lo que se transforma en límite discontinuo cuando es abisal, cuando la frontera no forma una sola línea indivisible, sino más de una línea en abismo y cuando, por consiguiente, no se deja ya trazar, ni objetivar, ni contar como una e indivisible" (Derrida, 2008, 47).

Pero "¿qué son los bordes de un límite que crece y se multiplica alimentándose de abismo?” (Derrida, 2008, 47). La contestación Derrida la expondrá a través de una tesis estructurada en tres enunciados. Según el primero, "Esta ruptura abisal no dibuja dos bordes, la línea unilineal e indivisible de dos bordes, el Hombre y el Animal en general" (Derrida, 2008, 47). Por medio del segundo sostendrá que "El borde múltiple y heterogéneo de esta ruptura abisal tiene una historia" (Derrida, 2008, 47), una genealogía tanto macroscópica como microscópica, la cual no estaría cerrada y para la que no dispondríamos de ninguna escala. Según Derrida no podría hablarse de historia más que presuponiendo ya una separación, desde uno de cuyos bordes, el de la "subjetividad antropo-céntrica", el hombre se contaría su historia, a la que se refiere como la Historia. Y por último, "Más allá del borde supuestamente humano, más allá de él pero en absoluto en 
un solo borde opuesto, en (el) lugar de 'El Animal' o de 'La-Vida-Animal', ya hay ahí una multiplicidad heterogénea de seres vivos" (Derrida, 2008, 47-48), o con mayor precisión ("decir seres vivos es ya decir demasiado y no lo bastante"), "una multiplicidad de organizaciones de relaciones entre lo vivo y lo muerto." Intimas y abisales, para Derrida no cabe pensar en una objetivación completa de esas relaciones, lo que impide en puridad cualquier referencia a algo así como "el Animal" en general.

\section{Conclusión: hacia otro se(gui)r en el mundo con los animales no humanos}

La delimitación entre el hombre y el animal que aquí hemos analizado se muestra como una de las cuestiones más difíciles de pensar, quizás la que más resistencia ha ofrecido, y sin embargo, lejos de haber servido de estímulo para la filosofía, en la mayoría de los discursos se ha resuelto sumariamente mediante un corte quirúrgico que en cada ocasión se pretendía definitivo para delimitarlos meridianamente. Sin haber suscitado apenas interés en sí mismos, la presencia de los animales no humanos en los textos filosóficos, especialmente desde la Modernidad, puede rastrearse principalmente siguiendo los diferentes presupuestos metafísicos que han trazado su esencialidad en paralelo a la del hombre.

Este sólido asentamiento metafísico no podía pasar desapercibido a Derrida, atento a escrutar las fisuras de esas anquilosadas zonas en las que se quiere dar a entender que ya no queda nada por pensar. La propuesta derridiana en ningún caso pasa por disolver esa frontera, alertando de que en ese caso el pensamiento se desactivaría naufragando en el biologismo, sino que busca cuestionarla, hacer ver que no es única, que no es clara, inquiriendo desde un racionalismo indoblegable los criterios que se han tenido por definitivos en la diferenciación del hombre de "lo que ellos llaman el animal".

Como hemos visto, para Derrida el límite entre el hombre y el animal tiene enormes implicaciones en el campo de la responsabilidad y de la decisión, todas ellas de gran actualidad en el marco de la creciente sensibilidad en nuestras sociedades hacia los modos de relacionamos con los animales, por ejemplo respecto al debate sobre sus derechos, al desarrollo legislativo que regula el trato, al vegetarianismo, al ecologismo y a la conservación de la biodiversidad, a la manipulación genética, a la intensificación creciente de su explotación, a las campañas contra la tortura animal, etc. Pero además ese límite presenta aristas de inconmensurable 
calado para el propio ámbito filosófico-ontológico, permitiendo al cuestionarlo que mane otro pensamiento de los animales en el que encaje mejor lo que la ciencia en su avance va descubriendo sobre ellos.

Enmendando a aquellos que ven en la deconstrucción un movimiento aniquilador, en el tratamiento de la cuestión animal se realza su marcada propensión afirmativa, al permitir que afloren detrás del "ello se deconstruye" nuevas posibilidades para el pensar. En el caso de "el animal”, concepto de enorme peso filosófico bajo el que los animales habrían sufrido una especie de ontifosilización para servir de mampostería en la que asentar las convicciones sobre nosotros mismos, surge ahora en toda su complejidad un "ello (nos) mira", que, a la par que mina dichas convicciones, nos interpela para abrir la ética a espacios desde los que poder replantearnos las disímiles y extremas formas de se(gui)r en el mundo con ellos. 


\section{Bibliografía}

Carranza, J. y col. (1994). Etología. Introducción a la Ciencia del Comportamiento. Cáceres, Universidad de Extremadura.

Cragnolini, M. B. (Dir.) (2008). Por amor a Derrida. Buenos Aires, La Cebra.

De Peretti, C.; Vidarte, P. (1998). Derrida. Madrid, Ediciones del Orto.

Derrida, J., (2008). El animal que luego estoy si(gui)endo. Traducción castellana de C. de Peretti y C. Rodríguez Marciel. Madrid, Trotta.

Derrida, J.; Roudinesco, E. (2009). Y mañana qué... Traducción castellana de Víctor Goldstein. Buenos Aires, Fondo de Cultura Económica.

Descartes, R. (2002). Meditaciones metafísicas. Trad. Juan Gil Fernández y Consuelo Bergés. Barcelona, Folio.

Heidegger, M. (2007). Los conceptos fundamentales de la metafísica. Mundo, finitud, soledad. Traducción castellana de Alberto Ciria. Madrid, Alianza Editorial.

Hickman, Cl. P. y col. (2009). Principios integrales de zoología, Madrid, Mc GrawHill.

Nietzsche, F. (1983). Más allá del bien y del mal. Traducción castellana de Andrés Sánchez Pascual. Madrid, Ed. Orbis.

Revista ARCHIPIÉLAGO (2007) no 75, Barcelona, Ed. Archipiélago.

Recibido : 24/09/2015

Aceptado : 05/10/2015

\section{(9) $\mathbb{Q \Theta O}$}

ENDOXA está bajo una licencia de Creative Commons Reconocimiento-NoComercial-SinObraDerivada 4.0 Internacional 